Acta Technologica Agriculturae 2

Nitra, Slovaca Universitas Agriculturae Nitriae, 2017, pp. 29-35

\title{
PREDICTION OF THERMAL PROPERTIES OF SWEET SORGHUM BAGASSE AS A FUNCTION OF MOISTURE CONTENT USING ARTIFICIAL NEURAL NETWORKS AND REGRESSION MODELS
}

\author{
Ramana GOSUKONDA*, Ajit K. MAHAPATRA, Daniel EKEFRE, Mark LATIMORE, Jr. \\ College of Agriculture, Family Sciences and Technology, Fort Valley State University, Fort Valley, USA
}

\begin{abstract}
Artificial neural networks (ANN) and traditional regression models were developed for prediction of thermal properties of sweet sorghum bagasse as a function of moisture content and room temperature. Predictions were made for three thermal properties: 1) thermal conductivity, 2) volumetric specific heat, and 3) thermal diffusivity. Each thermal property had five levels of moisture content $(8.52 \%, 12.93 \%, 18.94 \%, 24.63 \%$, and $28.62 \%$, w. b.) and room temperature as inputs. Data were sub-partitioned for training, testing, and validation of models. Backpropagation (BP) and Kalman Filter (KF) learning algorithms were employed to develop nonparametric models between input and output data sets. Statistical indices including correlation coefficient $(R)$ between actual and predicted outputs were produced for selecting the suitable models. Prediction plots for thermal properties indicated that the ANN models had better accuracy from unseen patterns as compared to regression models. In general, ANN models were able to strongly generalize and interpolate unseen patterns within the domain of training.
\end{abstract}

Keywords: ANN; sweet sorghum bagasse; moisture content; thermal properties

Sweet sorghum (Sorghum bicolor [L.] Moench) bagasse (SSB) is a promising raw material (Khalil et al., 2015) for thermal decomposition processes and production of bio-oil, gaseous fuels and biochar (Zhang et al., 2007). The response of biomass to heat transfer is dependent on thermal properties such as thermal conductivity $(\mathrm{k})$, thermal diffusivity $(\alpha)$ and specific heat $(\mathrm{Cp})$ of the biomass. Knowledge of these thermal properties are thus important not only for designing optimal processing systems but also for the prediction and control of various changes occurring in biomass during thermal processing and storage (Božiková and Hlaváč, 2013; Božiková et al., 2015; Yang et al., 2002).

Empirical equations for predicting thermal properties as a function of moisture content have been developed (Baika and Mittal, 2003; Farinua and Baika, 2007). However, artificial neural network (ANN) modelling has been increasingly accepted in predicting thermal properties of food and bioproducts (Sablani and Rahman, 2003; Kurta and Kayfecib, 2009; Ajasa et al., 2014). This may be due to the fact that ANNs allow nonlinear relations between the independent and dependent variables, and allow all possible interactions between the dependent variables (Sargent, 2001; Hajmeer and Basheer, 2002). Specially, non-linearity and noise tolerance characteristics allow ANNs to fit the data better, and to predict accurately (Gosukonda et al., 2015).

Applications of ANN in food and bioproduct research are reported to have performed better than standard statistical methods (Sarle, 1994; Panagou et al., 2011). For example, an ANN model trained with backpropagation is one word, remove hyphen (BP) algorithm predicted wood thermal conductivity with an $R^{2}$ of 0.99 and a root mean square (RMS) error of 0.012 (Avramidis and Iliadis, 2005). It demonstrates the inherent ability of ANNs to handle high biological variability (Zou et al., 2008; Sablani et al., 2002) and the uncertainty associated with thermal properties of various bioproducts. To our knowledge, use of ANN in predicting thermal properties of SSB has never been reported. In this study, ANN models were developed to predict thermal properties of SSB as a function of moisture content.

\section{Material and methods}

\section{Multi-layer perceptron (MLP) architecture}

A majority of neural networks applications to date use some form of Multi-Layer Perceptron (MLP) due to its universal approximation (White, 1992) and the compactness of its representation (Fig. 1). Since selection of a network structure and its parameters is usually done by trial and error (Najjar et al., 1997), use of commercial neural network software is convenient in finding the best network model with ease.

In this study, NeuralWorks Predict software (NeuralWare, Carnegie, PA) was employed to build models. Typically, Predict $^{\circledast}$ constructs the actual MLP neural network incrementally using cascade learning for determining a suitable number of hidden nodes (Fahlman and Lebiere, 1990) and it does not assume a fixed number of hidden units in advance (Gosukonda et al., 2015). 


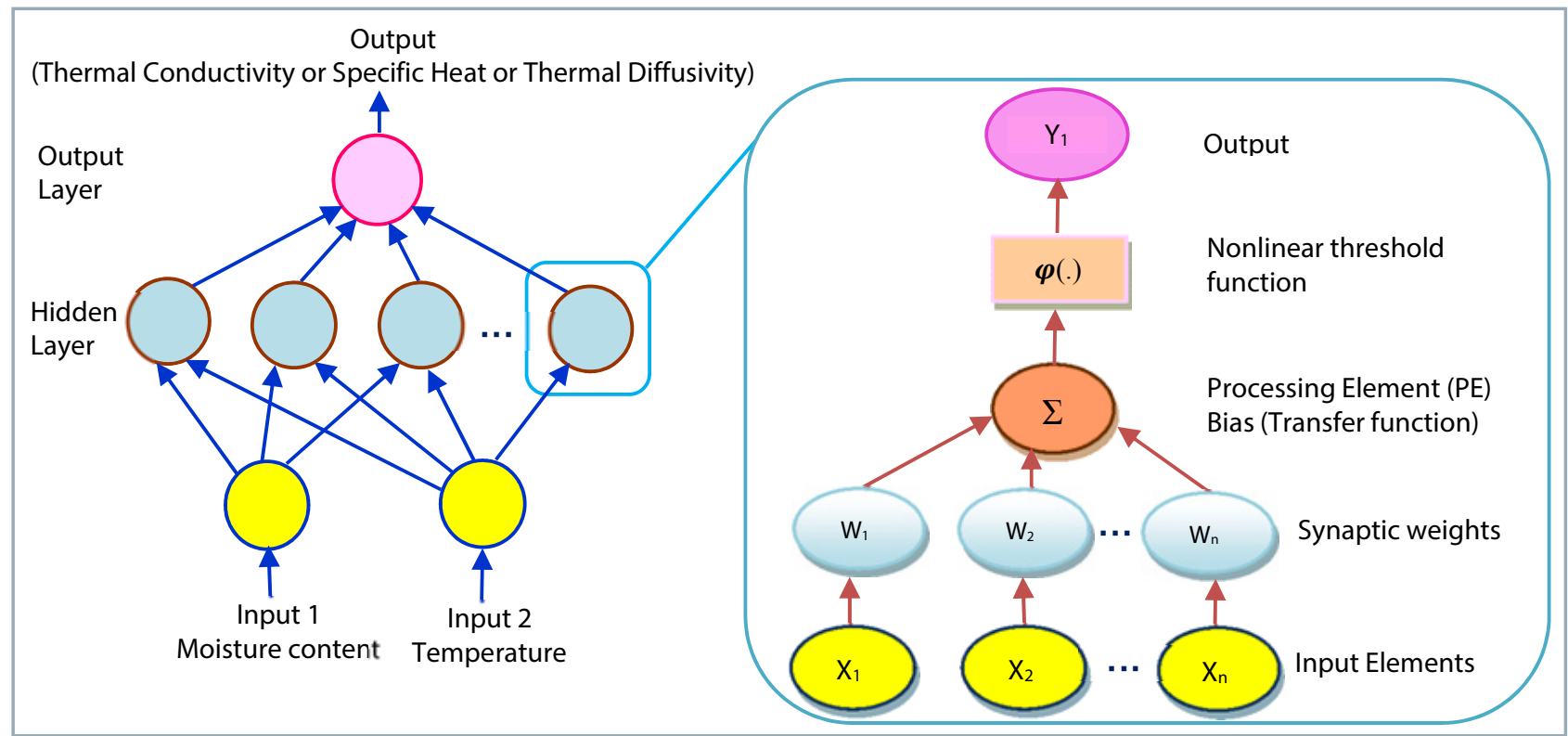

Fig. 1 Multilayer perceptron ANN consisting of input, hidden and output layers

Graphical representation of MLP (Fig. 1) shows the input layer consisting of two neurons which correspond to moisture content and temperature of SSB. The output has one neuron representing a single thermal property such as $k, C_{p}$, or $\alpha$. In this study the internal activity of neuron was transformed through a non-linear sigmoid function. When the transfer function is sigmoidal, the process of solving for the weights for a single processing element is equivalent to logistic regression (Sarle, 1994). The objective function, RMS error, was used to measure how closely the outputs of the network match the target outputs in the training data set.

\section{ANN learning algorithms}

Backpropagation (BP) and Kalman Filter (KF) learning rules were used because they minimize the expected value of error incrementally (Ruck et al., 1992). Also, KF has the inherent ability to suppress noisiness of the data (Haykin, 1999). The data sets were assumed to contain moderate to high noisiness during the model development.

\section{Collection of thermal properties data}

The data were obtained from experiments conducted at the Food Engineering Laboratory, Fort Valley State University that measured three thermal properties of SSB as a function of moisture content (\%, w. b.). The measured (outputs) thermal properties were:
1. thermal conductivity, $k\left(\mathrm{~W} \mathrm{~m}^{-1} \mathrm{~K}^{-1}\right)$,

2. volumetric specific heat, $C_{p}\left(\mathrm{MJ} \mathrm{m}^{-3} \mathrm{~K}^{-1}\right)$,

3. thermal diffusivity, $\alpha\left(\mathrm{mm}^{2} \mathrm{~s}^{-1}\right)$.

Thermal properties were measured at five levels of moisture content $(8.52 \%, 12.93 \%, 18.94 \%, 24.63 \%$, and $28.62 \%$, w. b.). Since the room temperatures were not constant, the temperature was included as an input variable for model development.

\section{ANN training, testing, and validation}

Each data set was subdivided for training, testing, and validation of ANN models. Training data were fed to ANN models to produce a formula that can capture essential relationships between moisture content (input) and thermal properties (output) and then they were subjected to generalization using testing data set, in which performance of model's interpolation was measured from a new set of inputs (i.e., testing data) to corresponding outputs. Validation set was independent of the training and testing data sets as it consisted of a separate set of records that were selected from the pool of available records. Validation data set was used to cross-test the prediction performance of ANN models (Plutowski and White, 1993). There were 150 records in each data set, of which 69 records were used for model training and 31 records for its testing. Remaining 50 records were used for validation of the model (Table 1 ).

Table 1 Distribution of data records in the three experimental data sets for each of the learning rules used in artificial neural network for training, testing, and validation purposes

\begin{tabular}{|c|c|c|c|c|c|c|c|c|}
\hline \multirow[t]{2}{*}{ Data Set } & \multicolumn{2}{|c|}{$\begin{array}{c}\text { Regression } \\
\text { (no of records) }\end{array}$} & \multicolumn{3}{|c|}{$\begin{array}{l}\text { Backpropagation rule } \\
\text { (no of records) }\end{array}$} & \multicolumn{3}{|c|}{$\begin{array}{l}\text { Kalman Filter rule } \\
\text { (no of records) }\end{array}$} \\
\hline & input set & $\begin{array}{c}\text { validation } \\
\text { set }\end{array}$ & train set & test set & $\begin{array}{c}\text { validation } \\
\text { set }\end{array}$ & train set & test set & $\begin{array}{c}\text { validation } \\
\text { set }\end{array}$ \\
\hline Thermal conductivity & 100 & 50 & 69 & 31 & 50 & 69 & 31 & 50 \\
\hline Specific heat & 100 & 50 & 69 & 31 & 50 & 69 & 31 & 50 \\
\hline Thermal diffusivity & 100 & 50 & 69 & 31 & 50 & 69 & 31 & 50 \\
\hline
\end{tabular}


Table 2

Performance statistics showing correlation (R) values for three thermal properties of sweet sorghum bagasse, using statistical regression models and neural network models

\begin{tabular}{|c|c|c|c|c|c|c|c|c|c|c|c|c|}
\hline \multirow[t]{3}{*}{ Data set } & \multicolumn{4}{|c|}{ Regression model } & \multicolumn{4}{|c|}{$\begin{array}{l}\text { Backpropagation learning } \\
\text { (neural network model) }\end{array}$} & \multicolumn{4}{|c|}{$\begin{array}{c}\text { Kalman filter } \\
\text { (neural network model) }\end{array}$} \\
\hline & \multicolumn{2}{|c|}{ training ${ }^{* *}$} & \multicolumn{2}{|c|}{ interpolation* } & \multicolumn{2}{|c|}{ training ${ }^{* *}$} & \multicolumn{2}{|c|}{ interpolation* } & \multicolumn{2}{|c|}{ training** } & \multicolumn{2}{|c|}{ interpolation* } \\
\hline & $\mathbf{R}$ & STD & $\mathbf{R}$ & STD & $\mathbf{R}$ & STD & $\mathbf{R}$ & STD & $\mathbf{R}$ & STD & $\mathbf{R}$ & STD \\
\hline $\begin{array}{l}\text { Thermal } \\
\text { conductivity }\end{array}$ & 0.73 & 0.008 & 0.67 & 0.008 & 0.77 & 0.008 & 0.72 & 0.008 & 0.74 & 0.008 & 0.75 & 0.008 \\
\hline Specific heat & 0.77 & 0.038 & 0.52 & 0.036 & 0.78 & 0.378 & 0.52 & 0.034 & 0.64 & 0.039 & 0.71 & 0.034 \\
\hline $\begin{array}{l}\text { Thermal } \\
\text { diffusivity }\end{array}$ & 0.84 & 0.015 & 0.76 & 0.013 & 0.85 & 0.014 & 0.78 & 0.013 & 0.84 & 0.015 & 0.95 & 0.013 \\
\hline
\end{tabular}

\section{Selection of an optimal ANN configuration}

Several network configurations were approached empirically and performances were compared using statistics with respect to training and test data sets. They were correlation coefficient $(R$, calculated using Pearson regression), standard deviation, average absolute error (Avg. Abs), maximum absolute error (Max. Abs), root mean square error (RMS), accuracy (the percent of predicted values that lie within $20 \%$ of their corresponding target output), and 95\% confidence interval, mean relative percentage residual (MRPR), bias factor, and mean absolute relative residual (MARR). Best models were selected based on $R$ values, as they measured the strength and direction of a linear relationship between predicted and targeted values. The evaluation of $R^{2}$ (coefficient of determination) is an inadequate measure for nonlinear models (Spiess and Neumeyer, 2010), as it requires its error term to be distributed normally.

\section{Statistical modelling}

To compare with ANN models, statistical regression models were developed to evaluate the quantitative impact of factors of interest (i.e., moisture content and room temperature) on the thermal properties of SSB. Following the same pattern as in the ANN modelling, 100 of the 150 measured values were used to fit the regression model (Table 1) and the remaining 50 observations were used to validate the model. Models were developed using PROC REG (regression procedure) and GLM (general linear models) procedures of Statistical Analysis Systems (SAS version 9.3). Prediction values were averaged for plotting the performances of models at each moisture level, as discussed by Wang and Brennan (1993).

\section{Results and discussion}

\section{Regression equations}

With multiple comparisons among linear, nonlinear, and polynomial models, the following regression equations were selected because of their better fit with the experimental data with relatively lower standard deviation and a larger regression coefficient.

$$
\begin{aligned}
k\left(\mathrm{~W} \mathrm{~m}^{-1} \mathrm{~K}^{-1}\right)= & 0.00378+0.00086 \times \text { moisture content }+ \\
& 0.00350 \times \text { temperature }
\end{aligned}
$$

$$
\begin{aligned}
C_{p}\left(\mathrm{MJ} \mathrm{m}^{-3} \mathrm{~K}^{-1}\right)= & 0.48409-0.00270 \times \text { moisture content }+ \\
& 0.01202 \times \text { temperature } \\
\alpha\left(\mathrm{mm}^{2} \mathrm{~s}^{-1}\right)= & 0.05768+0.00171 \times \text { moisture content }+ \\
& 0.00228 \times \text { temperature }
\end{aligned}
$$

\section{Performance of ANN and statistical models}

Performances of ANN and regression models for prediction of thermal conductivity $(k)$, volumetric specific heat $\left(C_{p}\right)$, and thermal diffusivity $(\alpha)$ of SSB were shown in Table 2 .

Though the data were partitioned to be used in training and testing phases of models, the software still used test data records implicitly during the model building. Heuristics involving performance on the test data were used as well to guide the choices during model building (NeuralWorks Predict $\left.^{\circledast}, 2013\right)$. For this reason, the performances ( $R$ value and STD) of training and test data sets were combined and shown as results of "training" column in Table 2. In general, ANN models trained with both BP and KF rules produced $R$ values of 0.77 and 0.74 for thermal conductivity, 0.78 and 0.64 for specific heat, and 0.85 and 0.84 in the training phase, respectively. ANN trained with $\mathrm{KF}$ produced the highest $R$ value (0.95) for predicting thermal diffusivity.

The range of $R$ values produced by regression models on input (training data) were $0.73,0.77$, and 0.84 for thermal conductivity, specific heat, and thermal diffusivity, respectively (Table 2 ). Regression models followed the similar patterns as those of ANN models.

\section{Comparison of statistical indices}

Table 3 shows the comparison of selected statistical indices. The MRPR results on validation data indicated that both ANN and regression models have over-predicted thermal conductivity (from $8 \%$ to $14 \%$ ), and thermal diffusivity (from $13.45 \%$ to $14.33 \%$ ), but under-predicted specific heat by $2.23 \%$ to $4.05 \%$. The bias factor values for specific heat for both ANN and the regression models were close to one indicating that there was no systematic bias (under or over protection). Mean absolute relative residual (MARR, \%) and accuracy factor are similar statistics, where they both measure the average deviation of predicted values from experimental values. The difference between these two is that an MARR value of 3.37 for specific heat by ANN model trained with $\mathrm{KF}$ indicates that the predicted values are either $3.37 \%$ above or below the experimental values. However, for 
Table 3 Comparison of statistical indices between ANN and regression models

\begin{tabular}{|c|c|c|c|c|c|}
\hline \multirow[t]{2}{*}{ Statistic } & \multirow[t]{2}{*}{ Model } & \multirow[t]{2}{*}{ Data set } & \multicolumn{3}{|c|}{ Thermal property } \\
\hline & & & thermal conductivity & specific heat & thermal diffusivity \\
\hline \multirow{6}{*}{$\begin{array}{l}\text { Mean relative } \\
\text { percentage residual } \\
\text { (MRPR) (\%) }\end{array}$} & \multirow{2}{*}{ regression } & input* & -7.86 & 2.59 & -14.33 \\
\hline & & validation & -10.19 & 2.63 & -14.28 \\
\hline & \multirow{2}{*}{$\begin{array}{l}\text { backpropagation } \\
\text { (ANN) }\end{array}$} & train & -10.87 & 3.93 & -13.52 \\
\hline & & validation & -13.73 & 4.05 & -13.45 \\
\hline & \multirow{2}{*}{ Kalman filter (ANN) } & train & -11.05 & 2.53 & -13.44 \\
\hline & & validation & -14.79 & 2.23 & -14.13 \\
\hline \multirow{6}{*}{ Bias factor } & \multirow{2}{*}{ regression } & input* & 1.08 & 0.97 & 1.14 \\
\hline & & validation & 1.31 & 0.96 & 1.56 \\
\hline & \multirow{2}{*}{$\begin{array}{l}\text { backpropagation } \\
\text { (ANN) }\end{array}$} & train & 1.11 & 0.96 & 1.13 \\
\hline & & validation & 1.41 & 0.92 & 1.53 \\
\hline & \multirow{2}{*}{ Kalman filter (ANN) } & train & 1.11 & 0.97 & 1.13 \\
\hline & & validation & 1.45 & 0.97 & 1.53 \\
\hline \multirow{6}{*}{$\begin{array}{l}\text { Mean absolute } \\
\text { relative residual } \\
\text { (MARR) }\end{array}$} & \multirow{2}{*}{ regression } & input* & 8.34 & 3.53 & 14.40 \\
\hline & & validation & 8.41 & 3.97 & 14.37 \\
\hline & \multirow{2}{*}{$\begin{array}{c}\text { backpropagation } \\
\text { (ANN) }\end{array}$} & train & 11.05 & 4.28 & 13.88 \\
\hline & & validation & 11.52 & 4.31 & 13.89 \\
\hline & \multirow{2}{*}{ Kalman filter (ANN) } & train & 11.39 & 3.37 & 13.75 \\
\hline & & validation & 12.61 & 3.84 & 14.62 \\
\hline \multirow{6}{*}{ Accuracy factor } & \multirow{2}{*}{ regression } & input* & 1.08 & 1.10 & 1.38 \\
\hline & & validation & 1.08 & 1.10 & 1.38 \\
\hline & \multirow{2}{*}{$\begin{array}{c}\text { backpropagation } \\
\text { (ANN) }\end{array}$} & train & 1.11 & 1.03 & 1.13 \\
\hline & & validation & 1.11 & 1.04 & 1.14 \\
\hline & \multirow{2}{*}{ Kalman filter (ANN) } & train & 1.11 & 1.04 & 1.14 \\
\hline & & validation & 1.12 & 1.04 & 1.14 \\
\hline \multirow{6}{*}{$\begin{array}{l}\text { Root mean square } \\
\text { residual (RMSR) }\end{array}$} & \multirow{2}{*}{ regression } & input* & 0.01 & 0.03 & 0.02 \\
\hline & & validation & 0.01 & 0.03 & 0.02 \\
\hline & \multirow{2}{*}{$\begin{array}{l}\text { backpropagation } \\
\text { (ANN) }\end{array}$} & train & 0.01 & 0.04 & 0.02 \\
\hline & & validation & 0.01 & 0.04 & 0.02 \\
\hline & \multirow{2}{*}{ Kalman filter (ANN) } & train & 0.01 & 0.03 & 0.02 \\
\hline & & validation & 0.01 & 0.03 & 0.02 \\
\hline
\end{tabular}

*training data set of ANN was used to develop regression models

the same model, an accuracy factor of 1.04 suggests that the deviation of the predicted values from experimental values is about $4 \%$. Since residuals rather than predicted values are normalized in MRPR and MARR, they are better statistical indices than bias factor and accuracy factors for comparing models, because the objective of normalization is to homogenize the variance (mean sum of squares of residuals (Jeyamkondan et al., 2001)). In general, ANN performed better than regression models in predicting specific heat and thermal diffusivity, whereas regression models were better in case of thermal conductivity.

\section{Performance of models in predicting thermal conductivity}

As compared to regression $(R=0.73)$, ANN models better exhibited the patterns of measured values $(R=0.77$ and 0.75 for BF and KF rules, respectively) on training data set (Fig. 2). Similar trends were observed as well on validation data set by the BP and KF rules (Fig. 3). The results indicated that KF produced slightly better correlation $(R=0.75)$ than BP rule $(R=0.72)$ and regression $(R=0.67$ (Table 2)). Although models run on training data produced higher $R$ values as compared to models run on validation data (Table 2), the correlation values produced on validation data 


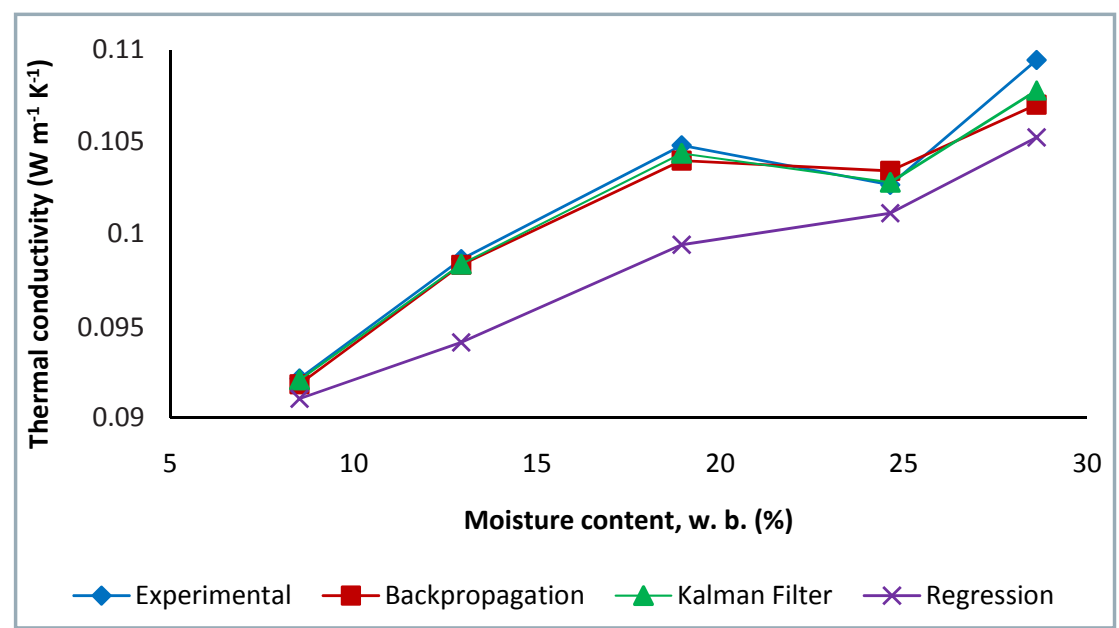

Fig. 2 Comparison between experimental and predicted values of thermal conductivity of sweet sorghum bagasse (training data set)

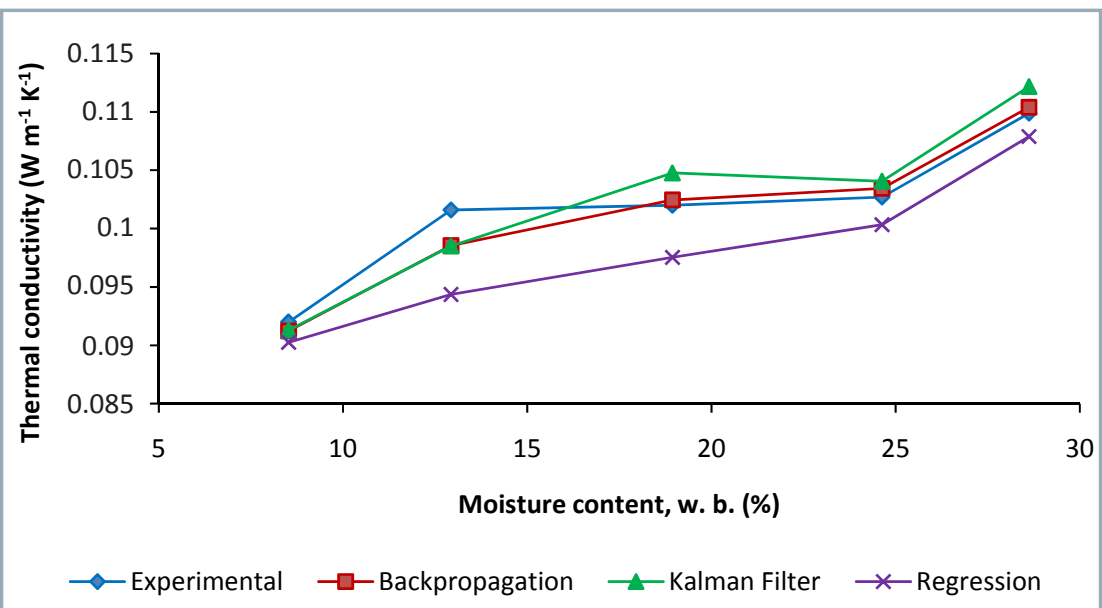

Fig. 3 Comparison between experimental and predicted values of thermal conductivity of sweet sorghum bagasse (validation data set)

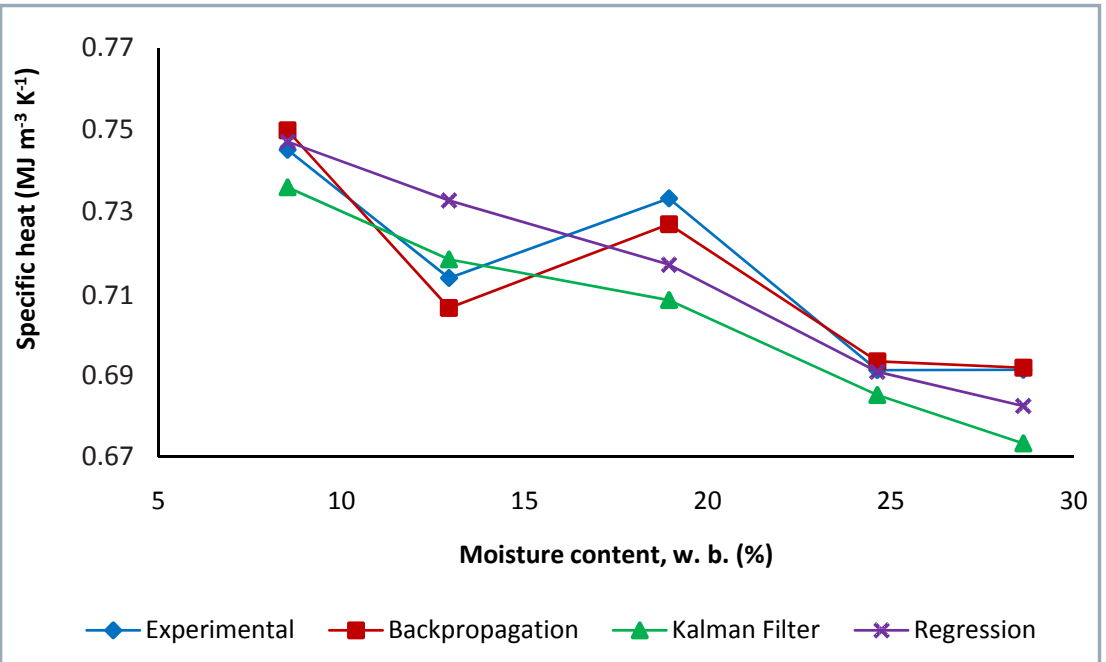

Fig. 4 Comparison between experimental and predicted values of specific heat of sweet sorghum bagasse (training data set) set further confirmed models' ability to predict accurately from unseen patterns. Pair-wise comparisons among the models for prediction of thermal conductivity from unseen patterns revealed that regression was significantly $(P<0.001)$ different from ANN models trained with BP or KF. However, there was no significant difference between BP and KF learning rules. Figs. 2 and 3 corroborate the results of original experiment where the average thermal conductivity of SSB increased with the increase in moisture content.

\section{Performance of models in predicting specific heat}

The Figs. 4 and 5 indicated that BP rule had better performance over KF and regression as its patterns were in alignment with the experimental values where the specific heat decreased with the increase in moisture content. Pair-wise comparisons of models on validation sets revealed that BP rule differed significantly $(p<0.001)$ from regression and KF. However, no difference was observed between KF rule and regression. Performances on training data (Table 2) indicated that there was no significant difference between BP $(R=0.78)$ and regression ( $R=0.77)$, but KF interpolated better $(R=0.71)$ than the other two models $(R=0.52)$.

\section{Performance of models in predicting thermal diffusivity}

The prediction performance on train data (Fig. 6) by all the models was comparable, as their $R$ values were $0.84,0.85$, and 0.84 for regression, $\mathrm{BP}$ and KF, respectively (Table 2). However, KF interpolated (Fig. 7) robustly $(R=0.95)$, followed by $\mathrm{BP}(R=$ $0.78)$ and regression model $(R=0.76)$. This could be due to KF's inherent ability to suppress noisiness in data (Sargent, 2001). The models support the experimental results, where the thermal diffusivity increased with the increase in moisture.

\section{Conclusions}

This study demonstrated that both ANN models and traditional multiple regression techniques could be used to predict thermal properties of 


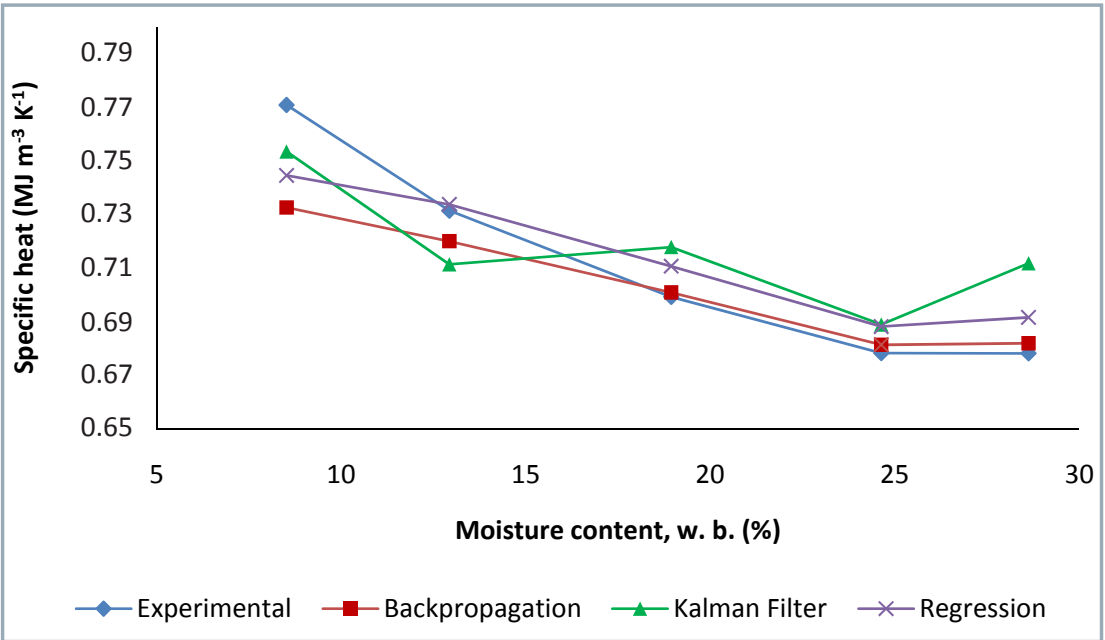

Fig. 5 Comparison between experimental and predicted values of specific heat of sweet sorghum bagasse (validation data set)

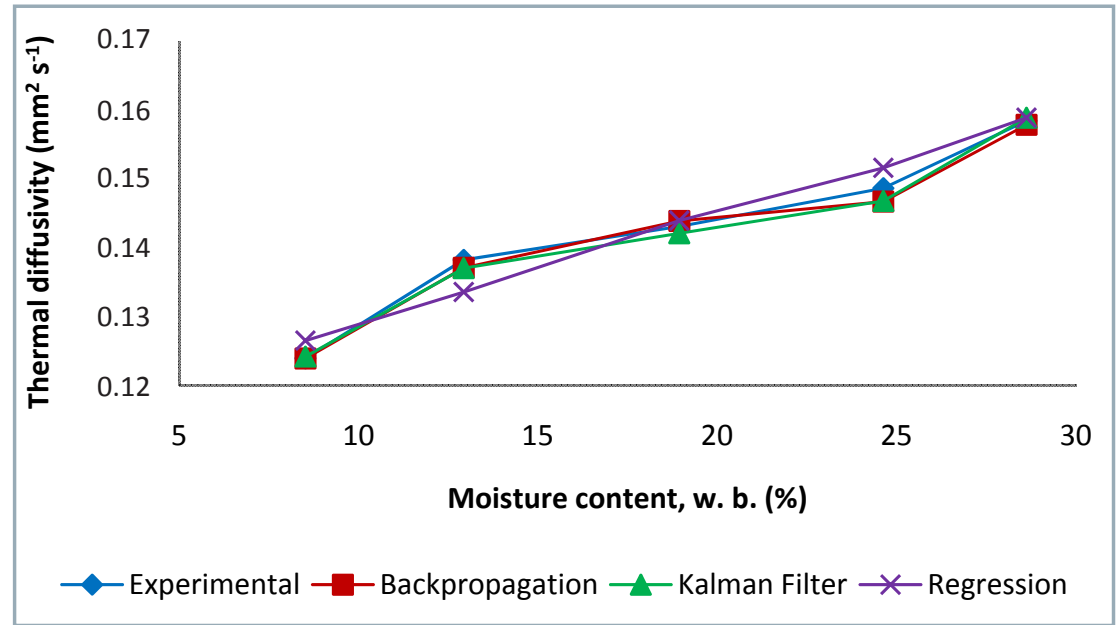

Fig. 6 Comparison between experimental and predicted values of thermal diffusivity of sweet sorghum bagasse (training data set)

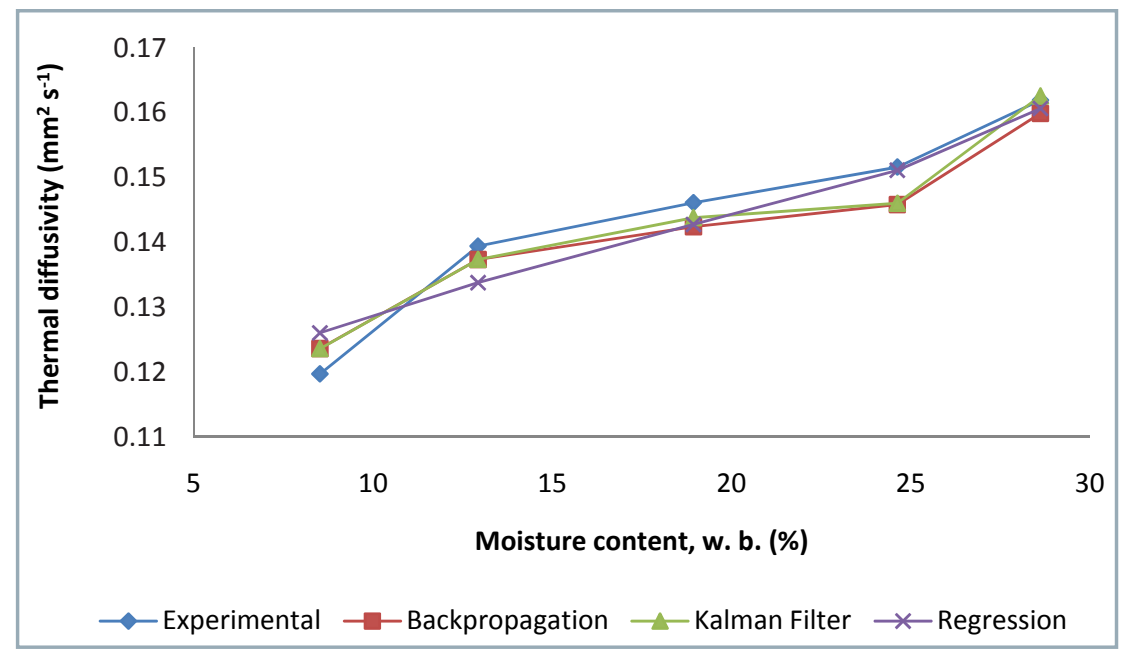

Fig. 7 Comparison between experimental and predicted values of thermal diffusivity of sweet sorghum bagasse (validation data set) sweet sorghum bagasse as a function of moisture content and room temperature. The main advantage of neural network models over statistical models was their ability to recognize the relationship between input and output data sets without specifying a priori relationship. Both KF and BP learning algorithms of multilayer perceptron have better correlation factors over regression models, especially in interpolating unseen patterns. Artificial neural networks models are similar to statistical techniques such as regression, especially when the emphasis is on prediction. This could be one of the explanations why the $R$ values of regression were so close to that of ANN models.

\section{Acknowledgements}

This material is based upon work that is supported by the National Institute of Food and Agriculture, U.S. Department of Agriculture, under award number 2010-38821-21570.

\section{References}

AJASA, A. A. - AKINYEMI, L. A. - SHOEWU, O. O. - ADENOWO, A. A. 2014. Exploitation of Artificial Neural Networks Approach to Predict the Thermal Conductivity of Food Products in Nigeria. In American Journal of Engineering Research, vol. 3, no. 3, pp. 22-29.

AVRAMIDIS, S. - ILIADIS, L. 2005. Predicting Wood Thermal Conductivity Using Artificial Neural Networks. In Wood and Fiber Science, vol. 37, no. 4, pp. 682-690.

BAIKA, O.-MITTAL, G. S.2003. Determination and Modeling of Thermal Properties of Tofu. In International Journal of Food Properties, vol. 6, no. 1, pp. 9-24.

BOŽIKOVÁ, M. - HLAVÁČ, P. 2013. Thermal conductivity and thermal diffusivity of biodiesel and bioethanol samples. In Acta Technologica Agriculturae, vol. 16, no. 4, pp. 90-94.

BOŽIKOVÁ, M. - HLAVÁČ, P. - VOZÁROVÁ, V. - BELÁN̆, L. 2015. Experimental determination of soft wheat flour thermal parameters. In Acta Technologica Agriculturae, vol. 18, no. 1, pp. 6-9.

FAHLMAN, S. E. - LEBIERE, C. 1990. The Cascade-Correlation Learning Architecture. In TOURETZKY, D. S. Advances in Neural Information Processing Systems 2. Los Altos, CA : Morgan-Kaufmann.

FARINUA, A. - BAIKA, O. 2007. Thermal Properties of Sweet Potato with Its Moisture 
Content and Temperature. In International Journal of Food Properties, vol. 10, no. 4, pp. 703-719.

GOSUKONDA, R. - MAHAPATRA, A. K. - LIU, X. - KANNAN, G. 2015. Application of Artificial Neural Network to Predict Escherichia coli 0157:H7 Inactivation on Beef Surfaces. In Food Control, vol. 47, no. 1, pp. 606-614.

HAJMEER, M. - BASHEER, I. A. 2002. A Probabilistic Neural Network Approach for Modeling and Classification of Bacterial Growth/NoGrowth Data. In Journal of Microbiological Methods, vol. 51, no. 2 , pp. 217-226.

HAYKIN, S. 1999. Neural Networks: A Comprehensive Foundation. ( $2^{\text {nd }}$ ed.). Upper Saddle River, NJ : Prentice Hall. ISBN 0132733501.

JEYAMKONDAN, S. - JAYAS, D. S. - HOLLEY, R. A. 2001. Microbial Modeling with Artificial Neural Networks. In International Journal of Food Microbiology, vol. 64, no. 3, pp. 343-354.

KHALIL, S. R. A. - ABDELHAFEZ, A. A. - AMER, E. A. M. 2015 Evaluation of Bioethanol Production from Juice and Bagasse of Some Sweet Sorghum Varieties. In Annals of Agricultural Science, vol. 60, no. 2, pp. 317-324.

KURTA, H. - KAYFECIB, M. 2009. Prediction of Thermal Conductivity of Ethylene Glycol-Water Solutions by Using Artificial Neural Networks. In Applied Energy, vol. 86, no. 10, pp. 2244-2248.

NAJJAR, Y. - BASHEER, I. - HAJMEER, M. 1997. Computational Neural Networks for Predictive Microbiology: I Methodology. In International Journal of Food Microbiology, vol. 34, no. 1, pp. 27-49. NeuralWorks Predict ${ }^{\oplus}$. 2013. The Complete Solution for Neural Data Modeling User Guide. Neuralware, Carnegie, PA. USA.

PANAGOU, E. Z. - MOHAREB, F. R. - ARGYRI, A. A. - BESSANT, C. M. NYCHAS, G. E. 2011. A Comparison of Artificial Neural Networks and Partial Least Squares Modelling for the Rapid Detection of the Microbial Spoilage of Beef Fillets Based on Fourier Transform Infrared Spectral Fingerprints. In Food Microbiology, vol. 28, no. 4, pp. 782-790.

PLUTOWSKI, M. - WHITE, H. 1993. Selecting Concise Training Sets from Clean Data. In EEE Transactions on Neural Networks, vol. 4, no. 2, pp. 305-318.

RUCK, D. W. - ROGERS, S. K. - KABRISKY, M. - MAYBECK, P. S. - MILLS, J. P. 1992. Comparative Analysis of Back-propagation and the Extended Kalman Filter for Training Multilayer Perceptrons. In IEEE Transactions on Pattern Analysis and Machine Intelligence (TPAMI), vol. 14, no. 6, pp. 686-691.
SABLANI, S. S. - BAIK, O. D. - MARCOTTE, M. 2002. Neural Networks for Predicting Thermal Conductivity of Bakery Products. In Journal of Food Engineering, vol. 52, no. 3, pp. 299-304.

SABLANI, S. S. - RAHMAN, M. S. 2003. Using Neural Networks to Predict Thermal Conductivity of Food as a Function of Moisture Content, Temperature, and Apparent Porosity. In Food Research International, vol. 36, no. 6, pp. 617-623.

SARGENT, D. J. 2001. Comparison of Artificial Neural Networks with Other Statistical Approaches: Results from Medical Data Sets. In Cancer, vol. 91, no. 8 (Supplementary), pp. 1636-42.

SARLE, W. S. 1994. Neural Networks and Statistical Models. In Proceedings of the Nineteenth Annual SAS Users Group International Conference, Cary, NC, pp. 1538-1550.

SAS. 2010. Users Guide: Statistics. Statistical Analysis System, Inc., Cary, NC : SAS Institute.

SPIESS, A. N. - NEUMEYER, N. 2010. An Evaluation of $R^{2}$ as an Inadequate Measure for Nonlinear Models in Pharmacological and Biochemical Research: a Monte Carlo Approach. In BMC Pharmacology, vol. 10, no. 6. Available at: http://doi. org/10.1186/1471-2210-10-6

WANG, N. - BRENNAN, J. G. 1993. The Influence of Moisture Content and Temperature on the Specific Heat of Potato Measured by Differential Scanning Calorimetry. In Journal of Food Engineering, vol. 19, no. 3, pp. 303-310.

WHITE, H. 1992. Artificial Neural Networks: Approximation and Learning Theory. Oxford: Blackwell Publishers.

YANG, W. - SOKHANSANG, S. - TANG, J. - WINTER, P. 2002. Determination of Thermal Conductivity, Specific Heat and Thermal Diffusivity of Borage Seeds. In Biosystems Engineering, vol. 82, no. 2, pp. 169-176.

ZHANG, Y. H. P. - DIN, S. Y. - MIELENZ, J. R. - CUI, J. B. - ELANDER, R. T, - LASER, M. 2007. Fractionating Recalcitrant Lignocellulose at Modest Reaction Conditions. In Biotechnology and Bioengineering, vol. 97, no. 1, pp. 214-33.

ZOU, J. - HAN, Y. - SO, S. S. 2008. Chapter 1. Overview of Artificial Neural Networks. In LIVINGSTONE, D. Artificial Neural Networks: Methods and Applications. New York: Humana Press, pp. 15-23. ISBN (soft cover) 9781617377389. 